\title{
Provinha Brasil e suas Interfaces no Cotidiano de uma Escola Pública da Baixada Fluminense
}

\author{
Provinha Brasil and Interfaces in Quotidian of a Public School \\ from Baixada Fluminense
}

\author{
Maria Océlia Mota* \\ Pontifícia Universidade Católica, PUC-Rio
}

\begin{abstract}
Este estudo foi realizado em uma turma do $2^{\circ}$ ano do ensino fundamental, em uma escola pública do município de Duque de Caxias no estado do Rio de Janeiro. O trabalho buscou pistas e indícios das possíveis implicações da Provinha Brasil no cotidiano escolar, procurando compreender como elas são ressignificadas pelos sujeitos participantes do cotidiano escolar e suas contribuições para a aprendizagem dos/as alunos/as. No campo teórico-metodológico, Ginzburg (1989) e Certeau (2012) proporcionaram as principais referências para investir no desafio da pesquisa do cotidiano. Para a construção dos dados foram utilizadas observação direta, entrevistas e análise de documentos. Como indício reativo e, também, de resistência, tanto a escola como a professora da turma $2 \mathrm{~B}$ demonstraram indiferença quanto ao uso da Provinha Brasil como diagnóstico e ajuda no planejamento pedagógico, o que implica desusos. As práticas investigadas na turma 2B transbordaram as barreiras da avaliação e revelaram a complexidade e multiplicidade dos fios que tecem o cotidiano escolar.
\end{abstract}

Palavras-chave: Avaliação, Alfabetização, Cotidiano escolar.

This study was conducted in a 2 nd year class of an elementary public school in the municipality of Duque de Caxias in state of Rio de Janeiro. The research sought clues and evidence of possible effects and implications of Provinha Brazil in school quotidian, trying to understand how they are re-signified by subjects participating in, the school context practitioners and their contributions to the students learning. In theoretical and methodological field, Ginzburg (1989) and Certeau (2012) provided the main references to invest in the challenge of school context research. For the construction of the data it was used direct observation, interviews and analysis of documents. As reactive clue and also resistance, both the school and the teacher of the class $2 \mathrm{~B}$ demonstrated indifference regarding the use of "Provinha Brazil" diagnosis and its help in educational planning, which implies disuses. The practices investigated in the class $2 \mathrm{~B}$ overflowed the barriers of the assessment and revealed the complexity and multiplicity of the threads that weave the school context.

Keywords: Evaluation, Literacy, School quotidian.

*Contacto: oceliamota@gmail.com

issn: $1989-0397$

www.rinace.net/riee/

https://revistas.uam.es/riee
Recibido: $\quad 4$ de julio de 2016

$1^{\text {a }}$ Evaluación: 20 de octubre de 2016

Aceptado: 15 de noviembre de 2016 


\section{Introdução}

Como objetivo principal, esta pesquisa buscou compreender as possíveis implicações das políticas de avaliações externas, especificamente a Provinha Brasil, no espaço tempo de aprender ensinar do cotidiano de uma turma de $2^{\text {a }}$ ano do ensino fundamental de uma escola pública da Baixada Fluminense no estado do Rio de Janeiro. Nesse sentido, investigar como elas podem interferir no cotidiano das instituições escolares a ponto de modificar (ou não) os fazeres da escola e do/a professor/a tornou-se imprescindível para percebermos como esses processos se desenvolvem e quais as suas consequências na aprendizagem dos/as alunos/as e no trabalho pedagógico desenvolvido pelos seus profissionais.

Entretanto, para compreendermos como esses efeitos se materializam e emergem no espaço escolar, demonstrando sua ambivalência, convêm que investiguemos o que se encontra por trás deles, problematizando-os, desconstruindo-os, relativizando-os. É preciso questioná-los, investigar o contexto socioeconômico e cultural da comunidade escolar estudada, mergulhar no seu cotidiano escolar para, assim, conhecer melhor a realidade desses alunos e dessas escolas que participam das avaliações externas, bem como a complexidade que envolve o tema. A pesquisa busca distinguir as operações quase microbianas que, segundo Certeau (2012, p. 41), "proliferam no seio das estruturas tecnocráticas e alteram seu funcionamento por uma multiplicidade de 'táticas' articuladas sobre os detalhes do 'cotidiano'”.

Este trabalho encontra-se articulado em três seções, além desta introdução. Na primeira seção, trazemos o contexto da pesquisa, o campo e seus atores escolares. Na segunda seção, apresentamos o discurso oficial da Provinha Brasil em confronto com os saberes e dizeres dos docentes, e, por fim, nas conclusões, buscamos refletir sobre os usos e desusos da Provinha Brasil na alfabetização, mostrando que, muitas vezes, as políticas públicas são ressignificadas pelos atores escolares, que se valem de táticas para reinterpretá-las a seu modo, de acordo com o contexto social e político em que se encontram imersos.

\section{2. $O$ contexto da pesquisa: $O$ campo e seus atores}

O campo definido para a realização da pesquisa foi uma escola municipal, localizada no município de Duque de Caxias. A turma selecionada foi do $2^{\circ}$ ano do ensino fundamental, por ser o ano em que é aplicada a Provinha Brasil. A turma $2 \mathrm{~B}$ e sua professora foram os principais participantes dessa pesquisa, além dos demais atores escolares que contribuíram, direta ou indiretamente, por meio de conversas, entrevistas, informações e documentos, todos/as foram participantes no processo da construção desse trabalho. O período de realização da pesquisa se deu entre os meses de outubro de 2012 e setembro de 2013, perfazendo um total de oitenta horas. A metade desse tempo, quarenta horas, foi destinado à observação direta em sala de aula, entre os meses de fevereiro e setembro de 2013, e as demais, com pesquisa documental, participação em Conselhos de Classe (COC), reuniões e demais eventos da/na escola, durante todo o percurso da investigação.

O município de Duque de Caxias, situado na periferia da cidade do Rio de Janeiro, fica na região da Baixada Fluminense. Segundo os últimos dados do Instituto Brasileiro de 
Geografia e Estatística (IBGE) de 2010, possui uma população de quase um milhão de habitantes 855.048 (oitocentos e cinquenta e cinco mil e quarenta e oito), com uma renda média de US\$ 67, 70 (sessenta e sete dólares e setenta centavos), sendo que $24 \%$ da população se encontram em idade escolar. A economia do município começou a ganhar relevo a partir da metade da década de 1990, impulsionada principalmente pela instalação da Refinaria de Petróleo de Duque de Caxias (REDUC). Em 1999, o Produto Interno Bruto (PIB) do município correspondia a 0,8\% do PIB nacional. Em 2002, passou a representar o sexto PIB brasileiro, com $1 \%$. Mas, esses números, que expressavam crescimento econômico não se traduziam em melhoras de vida para a população. O Índice de Desenvolvimento Humano (IDH) de Duque de Caxias foi, no ano 2000, o correspondente 0,753, ficando em $56^{\circ}$ lugar no estado e em $1796^{\circ}$ no Brasil, o que reflete as precárias condições de vida da classe popular, carente de saúde, educação de qualidade, saneamento básico etc.

Nesse contexto social, foi criada em 1999, a Escola Municipal Duque de Caxias ${ }^{1}$. A instituição veio atender a demanda escolar que crescera junto com as favelas Vila Ideal (Lixão) e Vila Nova que abrigavam o grande contingente de nordestinos e pessoas vindas de outras partes do país que chegavam ao Rio de Janeiro em busca de melhores condições de vida. A escola atende alunos/as da Educação Infantil ao $5^{\circ}$ ano do Ensino Fundamental. Em 2012, a escola atendia um total de 298 alunos/as, distribuídos em 14 turmas divididas igualmente em dois turnos. O prédio da escola é um sobrado, cercado por terrenos desocupados e uma imensa lixeira beirando um valão, onde porcos se refrescam em suas margens. Há uma pequena passarela por cima do valão que serve de acesso e ligação entre a favela e o bairro em que se localiza a escola, por onde os estudantes atravessam todos os dias.

A escola não possui um espaço apropriado para recreação, a cantina é um dos poucos espaços compartilhados pelos/as alunos/as e professores/as, também não possui biblioteca ou sala de leitura. A escola fica localizada numa região conhecida como "Faixa de Gaza", por causa dos constantes confrontos armados entre policiais e traficantes, fazendo com que instituição não funcione durante esses episódios, o que prejudica muito as atividades pedagógicas. A Escola Municipal Duque de Caxias encontra-se na mesma situação que milhares de escolas públicas brasileiras das grandes metrópoles, cercada por violência e ausência de serviços públicos mais básicos, como saneamento, moradia e saúde, apesar da escola pública ainda ser uma das poucas instituições do estado à qual as crianças têm acesso.

Para dar conta das peculiaridades da pesquisa, novos desafios se apresentavam: como apreender essa realidade? Que meios seriam capazes de dar conta de mostrar a multiplicidade e diversidade dos acontecimentos cotidianos? Nessa busca para captar elementos tidos muitas vezes como insignificantes e imperceptíveis, elegemos a pesquisa bibliográfica e documental, a observação participante, conversas/entrevistas, análise de documentos e fotografias. Esses meios nos forneceram o material que precisava para tecer os (desa)fios da pesquisa.

${ }^{1} \mathrm{O}$ nome da escola é fictício. 
No campo teórico-metodológico, o trabalho ancora-se no paradigma indiciário de Ginzburg (1989). Mas, pode um paradigma indiciário ser rigoroso? O próprio Ginzburg (1989, p. 179) faz essa pergunta, e ele mesmo trata de respondê-la, questionando se o tipo de rigor das ciências da natureza é não só inatingível, mas também indesejável para as formas de saber mais ligadas à experiência cotidiana. Mais precisamente, a todas as situações em que a unicidade e o caráter insubstituível dos dados são, aos olhos das pessoas envolvidas, decisivos.

Nessas situações, Ginzburg afirma que o rigor flexível do paradigma indiciário possibilita que a pesquisa do cotidiano não fique presa às amarras das metodologias cartesianas que engessam o conhecimento em uma forma na qual não há espaço para as experiências do cotidiano. Rigor este que, para Esteban (2003, p. 136), não pode "desconsiderar a necessidade de formulações teórico-metodológicas que conduzam o processo de pesquisa de forma rigorosa e responsável" e que "exige um claro compromisso com os sujeitos envolvidos no processo e com os resultados apresentados, mesmo sendo considerados parciais e provisórios". Ginzburg (1989, p. 150), alerta que "para encontrarmos as pistas e sinais é preciso estar (sic) atentos aos indícios imperceptíveis para a maioria”, e como um caçador, "aprender a farejar, registrar, interpretar e classificar pistas infinitesimais como fios de barba". É preciso, pois, desenvolver a capacidade de aprender a ler e interpretar os sinais, as pistas, os indícios metamorfoseados na realidade do cotidiano.

Seguindo a trilha do pensamento de Certeau (2012), vamos compreendendo que a pesquisa do cotidiano se inventa com "mil maneiras de caça não autorizada". É o autor quem nos propõe algumas maneiras de pensar as práticas cotidianas dos consumidores e nos ensina a captar as mil maneiras de fazer e usar dos usuários, na sua reapropriação do espaço organizado pelas técnicas de produção sociocultural. Certeau (2012) nos ensina que as conversas ordinárias com os praticantes desse espaço, ganham uma nova conotação. Todos os dados que poderiam ser desconsiderados ou desprezados são de extrema relevância e vão apontando as pistas e sinais para desvelarmos os efeitos dos exames padronizados no cotidiano escolar, enxergando as particularidades próprias de cada escola.

$\mathrm{Na}$ escola, podemos perceber esses usos e maneiras de fazer "não autorizadas" nas práticas pedagógicas de ensino/aprendizagem e avaliações que se encontram fora do script, ou seja, na maioria das vezes, os professores/as conseguem "mudar/adaptar ou reinterpretar" as regras do jogo do seu jeito, ou do jeito que a situação e o momento permitem que se faça. Os alunos, por sua vez, também se valem de táticas não previstas no regimento escolar, ou mesmo no planejamento da professora, para realizar outras formas e maneiras de aprender, compreender e compartilhar os conhecimentos, tanto os que trazem consigo, como aqueles que são oferecidos pela escola.

Nesse contexto, algumas questões foram norteadoras da pesquisa: que efeitos e modificações a Provinha Brasil vêm provocando no cotidiano das práticas pedagógicas dos/as professores/as na alfabetização? Como os/as professores/as se apropriam e utilizam a Provinha Brasil e seus resultados? As avaliações da aprendizagem realizadas na alfabetização têm sido significativas, a ponto de auxiliar no processo de ensinoaprendizagem dos/as alunos/as? 


\section{Provinha Brasil: Entre o texto oficial e a fazeres/dizeres docentes}

De acordo com os dados disponíveis do censo demográfico de 2010, realizado pelo IBGE, 3,3\% de indivíduos na faixa etária de 6 a 14 anos estão fora da escola. Esse percentual se traduz em uma quantidade de 966 mil crianças e adolescente que estão excluídos do acesso à escolarização. Das grandes regiões, a sudeste foi a que obteve o menor valor deste indicador $(15,0 \%)$, ficando os maiores índices com as regiões norte e nordeste, ambas com $18,7 \%$. Na história desse país, tanto a alfabetização como os professores alfabetizadores sempre foram desvalorizados e invisibilizados, uma das consequências de décadas de descaso com a educação, se refletiram nos resultados dos exames padronizados realizados pelo governo federal.

As políticas de avaliação foram implantadas no país a partir da década de 1990, com o objetivo de obter dados para subsidiar as políticas públicas e poder acompanhar a qualidade da escola brasileira. Foi a partir dos resultados do Sistema de Avaliação da Educação Básica (Saeb), baseados nos dados de provas realizadas de maneira amostral em escolas públicas de todas as regiões do país, nas áreas de Língua Portuguesa e Matemática, que se veio ter um retrato da realidade educacional do país. O que se verificou com a análise dos dados Saeb do período de 1995 a 2003 foi uma insuficiência (médias obtidas abaixo da média mínima satisfatória) nos índices de desempenho dos alunos quanto às habilidades e competências esperadas para cada nível de ensino (Inep, 2013). Nesse período, em Língua Portuguesa, a média de desempenho decresce respectivamente, de 188,3 para 169,4 na $4^{\mathrm{a}}$ série (atual $5^{\circ}$ ano); de 256,1 para 232,0 na $8^{\mathrm{a}}$ série (atual $9^{\circ}$ ano) e de 298,0 para 262,3 no $3^{\text {a }}$ ano do Ensino Médio.

$\mathrm{O}$ que os dados também mostraram foi que, embora tenha acontecido uma grande expansão do acesso à escolarização por parte das crianças das classes populares, o mesmo não aconteceu em relação à aquisição e domínio das habilidades exigidas pela escola. Nesse caso, as avaliações revelaram a baixa aprendizagem dos alunos: muitos chegavam ao $5^{\circ}$ ano sem os conhecimentos básicos exigidos para leitura e escrita. Nesse contexto, as políticas de avaliação foram se sofisticando cada vez mais com o objetivo de obter informações mais abrangentes sobre a aprendizagem dos alunos.

Em 2005, o Saeb foi reformulado, passando a ser composto por dois processos avaliativos: Avaliação Nacional da Educação Básica (ANEB) e Avaliação Nacional do Rendimento Escolar (ANRESC), conhecida como Prova Brasil. Em 2007, a atenção das políticas públicas volta-se para alfabetização e é criada a Provinha Brasil.

A Provinha Brasil foi a primeira avaliação da alfabetização em âmbito nacional, porém, alguns estados como Ceará (2007), Minas Gerais (2005) e Espírito Santo (2008), já haviam iniciado experiências próprias com avaliações externas na alfabetização. Com a proposta de não ser uma avaliação classificatória, mas sim um instrumento pedagógico de diagnóstico da aprendizagem, a fim de fornecer informações sobre o processo de alfabetização para professores e gestores, a Provinha Brasil tem como objetivos principais:

a) avaliar o nivel de alfabetização dos educandos nos anos iniciais do ensino fundamental;

b) oferecer às redes e aos professores e gestores de ensino um resultado da qualidade da alfabetização, prevenindo o diagnóstico tardio das dificuldades de aprendizagem; e c) 
concorrer para a melhoria da qualidade de ensino e redução das desigualdades, em consonância com as metas e políticas estabelecidas pelas diretrizes da educação nacional. (INEP, 2013, p.6)

Segundo o mesmo documento, a Provinha Brasil vem sendo disponibilizada desde 2008, no início e no fim do ano letivo e seus resultados usados para aperfeiçoar e reorientar as práticas pedagógicas, "diferenciando-se" das demais avaliações pelo fato de fornecer respostas diretamente aos alfabetizadores e gestores da escola (INEP, 2013). Nesse sentido, surge a seguinte questão: como os alfabetizadores e gestores da escola pesquisada estão utilizando essa informação? Devido a sua aplicação ser realizada, muitas vezes, com atraso, o que temos presenciado é o sentimento de indiferença e descaso com essa avaliação por parte tanto dos/as professores/as como dos/a gestores/as. Ao ser questionada a respeito da relevância da Provinha Brasil para sua prática pedagógica, a professora da turma $2 \mathrm{~B}^{2}$ desabafou:

Para mim, não faz diferença nenhuma, é só mais um meio de avaliar e eu tenho os meus métodos de avaliar. Eu acho, sinceramente, que é um gasto de dinheiro e material. Se no lugar da Provinha fizessem um curso de como deveria ser a avaliação, para aqueles que não sabem avaliar, seria mais válido do que gastar tanto papel, que no final do ano é jogado fora. (Professora da turma $2 \mathrm{~B}$ )

Para que a Provinha Brasil cumpra seu propósito diagnóstico e não concorra para a desqualificação do trabalho docente, Villas Boas e Dias (2015, p. 51) defendem que ela "precisa ser inserida em uma cultura avaliativa que dê ênfase à conquista das aprendizagens por estudantes e professores e despreze atividades e atitudes classificatórias".

Nos anos de 2012 e 2013, a Provinha Brasil (que deveria chegar à escola entre os meses de março e abril) chegou ao final do primeiro semestre (julho). Diante disso, como pode servir para diagnosticar o nível de alfabetização das crianças e ser instrumento para que os/as professores/as planejem suas atividades, se haviam se passado mais de cinco meses de aula? Nesse sentido, a característica diagnóstica e o discurso que essa avaliação pode ajudar a orientar a prática pedagógica do/a professor/a alfabetizador perdem o sentido. Na turma 2B, o depoimento da professora confirma este esvaziamento da retórica oficial.

Essa avaliação não serve para orientar minha prática, ainda mais quando aplicada nesse perído. Nós fazemos o planejamento no início do ano letivo e não levamos a Provinha Brasil em consideração para realizá-lo. É um tipo de prova para constar, "cumprir tarefa", tentar medir não o conhecimento do aluno, mas o meu trabalho. Eu não preciso que uma avaliação externa me diga em que nível está meu aluno, já faço essa avaliação diariamente e acompanho as dificuldades e os avanços de cada um. (Professora da turma 2B)

A professora acha que "a prova não atende às necessidades pedagógicas, apenas avalia o trabalho do professor", o que quer dizer que, mesmo indiretamente, ela se sente afetada por essa avaliação. Afonso (2009, p. 46) alerta que "sejam ou não divulgadas publicamente informações sobre os resultados obtidos pelas escolas, este modelo de responsabilização fará sempre recair sobre os/as professores/as e gestores/as a justificação desses mesmos resultados”, o que, segundo o autor, pressupõe que estes tenderão a criar mecanismos de controle organizacional para garantir as condições necessárias a sua obtenção.

${ }^{2}$ Nome da turma fictício. 
A docente nos oferece pistas e indícios de processos de subversões, insubordinações a respeito da Provinha Brasil. Desse modo, os/as professores/as se opõem às regras e leis impostas verticalmente pelo Estado que, através da imposição de determinadas "ações", também não consideram os fazeres, nem os pensares das professoras alfabetizadoras. A professora de outra turma de alfabetização da mesma escola também compartilha do pensamento da professora da turma $2 \mathrm{~B}$ :

Pra mim, investir no aluno dentro de sala de aula é mais importante do que investir em uma avaliação desse tipo. É mais fácil perguntar pra mim que já sei há tanto tempo fazer avaliação e faço avaliação com meus alunos e conheço cada um dos meus alunos, porque essas provas são somente papel. Ele não conhece meu aluno, ele não sabe se naquele dia ele estava passando mal, não sabe se ele sofreu alguma violência, num (sic) conhece nada disso, mas eu conheço. Então por que não pede para eu avaliar, ou pelo menos, por que não leem os relatórios, que preenchemos aqui no município? (Professora B)

A professora $\mathrm{B}$, que atua nessa mesma escola há mais de dez anos e convive com todos os conflitos internos e externos da escola, mostra sua indignação diante de uma avaliação que desconsidera o conhecimento do/a professor/a respeito da aprendizagem de seus alunos. Na fala das docentes, está presente a indignação diante da desvalorização dos saberes da classe, ao reclamarem que se as professoras já fazem avaliações e conhecem seu aluno, por que não valorizar o seu conhecimento? Então, seria a Provinha Brasil capaz de atestar se o aluno já sabe ler e escrever? Não teria o/a professor/a competência para avaliar seus alunos, uma vez que os avalia cotidianamente? Para Esteban (2012),
a Provinha Brasil acompanha tendência percebida em outros exames estandardizados, inseridos em processos de avaliação externa, de reduzir as margens da autonomia docente, pelos mecanismos de controle ao qual se vincula, inclusive no que se refere ao planejamento cotidiano da prática pedagógica. O grau de regulação indica desconfiança sobre a capacidade docente de formulação e de compreensão de sua prática cotidiana. (p. 586)

Questionada se a Provinha Brasil provocou modificações na sua forma de avaliar ou trabalhar, a professora B continua:

\begin{abstract}
Não, não. Eu modifico a minha prática diante do que o aluno apresenta. Por isso, eu digo que a minha avaliação é que é importante. A partir do momento em que começo a avaliar meu aluno, sei quais são os caminhos que devo tomar com ele pra que ele aprenda de forma melhor, essa é minha avaliação. Aquele aluno ali, se eu colocar ele para decorar o bábébibóbú, ele vai ter segurança e vai continuar, o outro não, eu terei que fazer de forma mais lúdica. Porque eu conheço meu aluno e é isso que vai modificar minha prática. Eu não modifico meu planejamento por conta da Provinha e eu não me preocupo, e nessa não preocupação, os meus alunos acabaram tendo um bom desempenho. (Professora B)
\end{abstract}

As professoras se ressentem diante da desqualificação de seus saberes e de terem que "engolir" uma avaliação externa cujo preparo não contou com sua participação, mas que, mesmo indiretamente, terminará por responsabilizar o/a professor/a pelos resultados obtidos por sua turma. Segundo Silva e Cafiero (2010, p. 35), são vários os fatores que contribuem para um impacto não desejado das avaliações nas práticas escolares, entre eles, está o fato de que essas avaliações têm sido, de certa forma, impostas às escolas pelo sistema educacional do qual fazem parte. $\mathrm{O}$ fato de o/a professor/a não participar do processo de elaboração e de ser, muitas vezes, responsabilizado pelos maus resultados, segundo os autores, faz com que haja uma recepção negativa da avaliação no espaço escolar.

O caderno de reflexões sobre a prática da Provinha Brasil ressalta que seus resultados não serão utilizados na composição do Índice de Desenvolvimento da Educação Básica 
(Ideb). O desejável é que ela seja utilizada com o intuito de orientar as ações políticas e pedagógicas que poderão, em conjunto com outras iniciativas, melhorar os índices apresentados até o momento. Porém, o que fazem o/a professor/a e os/as gestores/as com o resultado da Provinha Brasil?

Eu apenas corrigi as provas, coloquei o número de questões que cada criança acertou e passei para um funcionário da secretaria, ele que ficou responsável, segundo orientações da orientadora, de fazer a sistematização dos dados que seriam enviados para a Secretaria de Educação do município. (Professora da turma 2B)

Até o mês de outubro de 2013, a Secretaria Municipal de Educação de Duque de Caxias ainda não havia dado nenhum retorno à escola. Podemos inferir disso tudo que até chegar ao chão da escola, o discurso ideal/oficial das políticas públicas sofre inúmeras interferências e é ressignificado de outras formas pelos sujeitos que tecem o cotidiano escolar. Diante das dificuldades dessas políticas serem postas em prática, constata-se que elas podem não fazer sentido para as pessoas que estão atuando naquele espaçotempo. Esses profissionais criam redes de subversões e, à maneira dos povos indígenas citados por Certeau (2012, p. 40), "fazem uma bricolagem com e na economia cultural dominante, usando inúmeras e infinitesimais metamorfoses da lei, segundo seus interesses próprios e suas próprias regras". Para a professora da turma $2 \mathrm{~B}$ :

\section{As avaliações têm que partir da escola, com a participação dos professores, baseada na própria realidade local, senão fica completamente descontextualizada e não tem muita utilidade (sic). No período em que ela foi aplicada, no final do primeiro semestre, não fez nenhuma diferença. (Professora da Turma 2B)}

A docente fala de uma avaliação democrática, participativa e diagnóstica, que seja pensada pela comunidade escolar, baseada na realidade e no contexto local, e que seja útil para as práticas pedagógicas dos professores e para a aprendizagem dos/as alunos/as. Entendendo que avaliar é preciso, Malavasi (2010, p. 87) vê a avaliação como uma prática necessária, que não ocorre naturalmente, mas que precisa ser incorporada como uma prática comum em todos os segmentos que participam da escola. Para a autora, avaliar a educação básica significa "atribuir aos gestores responsabilidades e critérios para a realização de uma avaliação criteriosa e seria que leve em conta as discussões de todo o grupo e aponte, através do anúncio de uma concepção de educação, o lugar que se deseja ocupar na educação de seus integrantes".

A Provinha Brasil, na verdade, é apenas um teste de verificação que mede algumas habilidades dos/as alunos/as, que são questionadas por algumas professoras, que acham que elas mesmas são capazes de realizar uma melhor avaliação de seus/suas alunos/as, haja vista a sua convivência cotidiana com eles/as. Até o primeiro semestre de 2011, o teste só avaliava as habilidades relativas à alfabetização e ao letramento inicial, mas a partir do segundo semestre de 2011, foi incorporada a avaliação de Matemática inicial. Os exames podem ser aplicados pelo/a próprio/a professor/a da turma com o objetivo de monitorar e avaliar a aprendizagem de cada aluno/a ou por pessoas indicadas e preparadas pela secretaria de educação.

Porém, o fato de ser o/a próprio/a professor/a da turma a realizar a aplicação, não implica que haja um envolvimento e uma aceitação desse profissional nesse instrumento de avaliação e nem que o/a mesmo/a se utilize dos recursos diagnósticos do exame. A proposta da Provinha Brasil é obter uma visão geral de cada escola, através dos resultados que são enviados para a secretaria de educação, para que os gestores da rede 
possam ter conhecimento de como se encontra a situação da aprendizagem das crianças, contando, assim, com elementos para subsidiar a elaboração de políticas educacionais (INEP, 2013).

Mas, será que esse exame tem sido um instrumento capaz de influenciar na melhoria da alfabetização das crianças, elevando a qualidade do ensino nas escolas públicas? Tem fornecido informações válidas o suficiente para direcionar novas políticas públicas? Há opiniões diversas entre alguns pesquisadores brasileiros, que nos levam a refletir a respeito do quanto o uso de um exame pode ser controverso.

Para Villas Boas e Dias (2015, p. 51), um instrumento como a Provinha Brasil "pode contribuir para a melhoria do processo de ensino-aprendizagem se for compreendida no interior das instituições educacionais e pelas políticas públicas e articulada com a avaliação da aprendizagem via avaliação institucional”. Já na visão de Arroyo (2010, p. 1402), "a Provinha Brasil e tantas provas oficiais são testes de capacidades dessa inserção precária sempre à beira de deslizar para os níveis mais graves da exclusão social, até dos felizardos que acertam acima da média”.

No Guia de Correção e Interpretação dos Resultados do kit da Provinha Brasil foram consideradas como habilidades imprescindíveis para o desenvolvimento da alfabetização e do letramento as que podem ser agrupadas em torno de cinco eixos: a) apropriação do sistema de escrita; b) leitura; c) escrita; d) compreensão e e) valorização da cultura escrita e desenvolvimento da oralidade. Porém, o Ministério da Educação e Cultura (MEC) (INEP, 2013) reconhece que, em função da natureza de um processo de avaliação como o da Provinha Brasil, a Matriz de Referência considera apenas as habilidades de três eixos: 1) Apropriação do sistema de escrita; 2) Leitura; e 3) Compreensão e valorização da cultura escrita. Entretanto, Esteban (2012) alerta que apenas os dois primeiros eixos são efetivamente incorporados ao exame, à prova e aos demais documentos que formam o kit Provinha Brasil, evidenciando seu caráter pragmático, redutor, por focalizar exclusivamente um conjunto de habilidades.

Oliveira e Silva (2011) realizaram uma pesquisa em que criticam os testes aplicados na alfabetização e analisam quais são as competências medidas nesses testes, os constructos sobre alfabetização implícitos ou explícitos nos indicadores e a robustez dos itens em relação aos indicadores. Dos cinco testes identificados pelos autores que se propõe a medir competências de alfabetização, a Provinha Brasil foi o que apresentou maior número de itens voltados para a decodificação, cerca de quatorze dos vinte e quatro itens. Por essa razão, eles concentraram a análise nesse teste. Como conclusão da pesquisa, constataram que "todas as matrizes utilizadas no Brasil para avaliar a alfabetização se baseiam em construtos que não apenas são mal especificados e inconsistentes com o conhecimento científico sobre o tema, mas também não foram validados empiricamente" (Oliveira e Silva, 2011, p. 836).

Em pesquisa realizada em 2008, com toda a rede pública do município de Camaragibe, no Recife, De Morais; Leal e Albuquerque (2009, p. 318) constataram que o uso da Provinha Brasil como instrumento de diagnóstico do nível de alfabetização dos alunos de uma rede de ensino não é suficiente para compreender os processos de aprendizagem das crianças e que, portanto, devem ser utilizados em articulação com outras estratégias que as próprias escolas são capazes de produzir. Os autores alertam para o atual quadro de incertezas sobre como alfabetizar, ainda reinante em nosso país, o que faz com que 
apostemos na necessidade de assegurarmos aos docentes seu direito à formação continuada. Nessa discussão teórica, De Morais (2015) defende outro ponto de vista, para o autor:

A Provinha pode servir como útil instrumento para que os docentes sejam auxiliados a ajustar o ensino às necessidades de seus alunos e para que as redes de ensino, nas quais trabalham, definam políticas claras de formação continuada de seus alfabetizadores, bem como sejam ajudadas a prescrever melhor os currículos de alfabetização que desejam praticar. (De Morais, 2015, p. 291)

Em recente pesquisa, em que correlacionava as práticas avaliativas no interior da escola pública com as avaliações externa no município de Duque de Caxias, Assumpção, em suas considerações finais em relação a Provinha Brasil, observou que:

os professores relatam que não se utilizam dos resultados desta prova para realizar a avaliação dos alunos e que os conhecimentos em pauta não revelam o dia a dia de seus alunos, oriundos das classes populares. Para exemplo, podemos considerar a utilização da cópia de um bilhete de cinema, em uma das questões da Provinha Brasil. (Assumpção, 2012, p. 84)

Assumpção realizou sua pesquisa em cinco escolas do município e entrevistou 24 professores distribuídos em escolas municipais de quatro diferentes distritos de Duque de Caxias, todos regentes do ensino fundamental. Oliveira R. M. (2012), em pesquisa realizada em uma escola pública do mesmo município, a respeito dos limites e possibilidades da Provinha Brasil no trabalho pedagógico do/a professor/a conclui que:

a Provinha Brasil, na escola analisada, não interfere no trabalho da professora alfabetizadora no sentido de alfabetizar e letrar melhor as crianças da sua turma. As informações coletadas por meio das observações das aulas, entrevistas e acompanhamento das atividades dos alunos da turma deixam claro que, as informações geradas por essa avaliação não orientaram o trabalho pedagógico para uma intervenção com intuito de promover avanços dos níveis de leitura e tão pouco a sua utilização como instrumento de diagnóstico que favoreça uma alfabetização de qualidade, nessa escola. (Oliveira, 2012, p. 62)

Oliveira (2012, p. 63) também constatou que a professora da turma em que realizou a pesquisa "não estava preocupada em refletir sobre os resultados da Provinha Brasil como possibilidade de melhorar a qualidade da alfabetização da sua turma”. Nesse sentido, a autora reconhece que, o sentido de diagnóstico proposto pela prova deixa de ser relevante tanto para a alfabetização de seus alunos como para uma análise do seu trabalho, já que a avaliação externa não é vista como algo que possa contribuir para o desenvolvimento do ensino/aprendizagem. As pesquisas de Assumpção (2012) e Oliveira (2012) vieram corroborar com as percepções e conclusões a respeito da Provinha, visto que o trabalho de ambas aponta a indiferença dos professores do ciclo básico de alfabetização em relação à Provinha Brasil.

\section{A Provinha Brasil: Usos e desusos no cotidiano escolar}

O que foi percebido nas quarenta horas de observação direta na turma $2 \mathrm{~B}$, e em conversas e entrevistas com as professoras alfabetizadoras e a equipe pedagógica foi que não houve nenhuma interferência da Provinha Brasil nas práticas pedagógicas da professora ou da equipe gestora da escola. Além disso, o atraso na chegada do material 
para a sua aplicação parecia não incomodar os profissionais da escola. O que aconteceu quando o material para a aplicação da prova chegou, como bem disse a professora, "é que ela foi aplicada apenas para constar”, para cumprir uma obrigação.

A professora não utilizou a ficha de avaliação que vem no Guia de Correção e Interpretação dos Resultados, preencheu as questões acertadas pela turma e o número de acertos de cada um em uma folha de ofício. Aparentemente, a docente pareceu não dar importância à verificação dos níveis de aprendizagem da turma e de cada aluno, ou seja, ela ignorou as informações contidas no Guia. Portanto, podemos inferir que tais resultados da Provinha Brasil não foram utilizados pela professora e nem pela escola, servindo apenas para serem enviados à Secretaria de Educação do município, que segundo a orientadora educacional, não fornece um feedback para a escola. Essa aparente indiferença da escola pela Provinha Brasil através de "operações quase microbianas" revelam indícios de subversões dos sujeitos ordinários que, para Certeau (2012), criam um jeito próprio de praticar essas políticas impostas, ressignificando e transformando-as em resistências.

Durante o período de observação em sala de aula e de análises dos cadernos de aula e de casa dos alunos, não foram encontradas pistas nem sinais da interferência da Provinha Brasil nos conteúdos trabalhados em sala de aula. Ou seja, verificou-se que o trabalho que a professora realiza vai muito além dos descritos na matriz curricular da Provinha Brasil, sendo muito mais abrangente. As atividades trabalhadas são completamente diferenciadas da formatação das questões da provinha, o que demonstra que a docente se preocupa com a aprendizagem das crianças e não com o "treinamento". O currículo praticado pela professora em sala de aula está em consonância com a proposta curricular da rede do município e este com o planejamento anual feito pela docente.

Na prática, as implicações da Provinha Brasil no cotidiano de uma turma do ciclo básico de alfabetização, como se percebeu, são reinterpretadas pelos sujeitos praticantes do cotidiano escolar, que revelou surpresa, e mostrou a multiplicidade e a diversidade dos seus praticantes. As professoras entrevistadas demonstraram ignorar a proposta de diagnóstico e intervenção proposta pela Provinha Brasil e seus resultados, o que caracteriza o seu desuso. Porém, ao não se recusarem a aplicá-la, terminam por usá-la, mesmo que o façam apenas para "cumprir tarefa", dessa forma, não a rejeitam, nem a transformam, mas a ressignificam ao seu modo. Para esses profissionais, não tem sentido uma avaliação que "vem de fora”, e que não leva em consideração as competências dos/as docentes para avaliar seus/suas próprios/as alunos/as. O depoimento da professora da turma $2 \mathrm{~B}$ representa essa desconsideração da prova pelos/as docentes.

\begin{abstract}
As avaliações fogem da realidade, ela não tem influência, por que elas só fazem parte do cotidiano da escola no momento em que vão ser aplicadas. Se essas políticas fossem mais presentes no planejamento, elas poderiam dar mais resultados, mas não é o caso, não adianta fazer uma avaliação que vem de fora e que não vai dar certo aqui, porque primeiro tem que partir daqui, de cada escola, de cada município e não fazer um pacote e achar que vai dar certo aqui. Eu acho que tem que ter avaliação sim, mas tem que trabalhar com os professores da própria rede. Eles é que tem que ver como é que vai essa avaliação, como é que vai ser montada, como é o público, como vai ser avaliada, colocada em prática. (Professora da turma $2 \mathrm{~B}$ )
\end{abstract}

Mesmo não interferindo no currículo praticado em sala de aula, nas conversas e entrevistas realizadas com a professora da turma $2 \mathrm{~B}$ e outras professoras da escola que atuavam no ciclo, foi perceptível o quanto essa política de avaliação afeta diretamente a 
subjetividade dos/as professores/as. Os docentes se mostram ressentidos diante da desconsideração de seus saberes e da perda de sua autonomia e pelo fato dessa avaliação não ser promovida e pensada pelos próprios atores escolares, nesse caso, os mais afetados.

As práticas investigadas na turma $2 \mathrm{~B}$ transbordaram as barreiras da avaliação e revelaram a complexidade e multiplicidade dos fios que tecem o cotidiano escolar. E, na contramão da lógica que valoriza e procura empurrar os sujeitos para a competição individual, o que se encontraram foram ações coletivas e compartilhadas dos/as alunos/as, que astuciosamente se aproveitam de cada brecha que a rotina escolar lhes oferece, inventando outras formas aprenderensinar, num processo de auto-organização, a fim de conquistar a tão sonhada alfabetização.

Em 2013, seis anos após sua criação, a Provinha Brasil, cuja função era somente diagnóstica, passou a ter um sistema informatizado para coleta e tratamento de seus resultados pelo MEC, que não mais ficarão restritos à escola e às secretarias municipais de educação. Nesse sentido, a prova ganha uma nova conotação, na medida em que seus resultados não ficam apenas na escola para uso dos professores e equipes pedagógicas, mas passam a fazer parte do controle dos órgãos governamentais, ganhando um caráter censitário.

\section{Referências}

Afonso, A. J. (2009). Avaliação educacional: Regulação e emancipação: Para uma sociologia das políticas avaliativas contemporâneas. São Paulo: Cortez.

Assumpção, E. A. (2013). Correlação das práticas avaliativas no interior da escola com a política de controle público por meio da avaliação: Um estudo em Duque de Caxias/RJ. (Dissertação de Mestrado). Universidade Federal do Estado do Rio de Janeiro, Rio de Janeiro.

Certeau, M. A. (2012). Invenção do cotidiano: Artes de fazer. Petrópolis, RJ: Vozes.

De Morais, A. G., Leal, T. F. e Albuquerque, E. B. C. (2009). Provinha Brasil: Monitoramento da aprendizagem e formulação de políticas educacionais. RBPAE, 25(2), 301-320.

De Morais, A. G. (2014). Precisamos de boas políticas públicas de avaliação da alfabetização: análise das razões de tal necessidade e de fatores que impedem que avancemos no cumprimento dessa republicana tarefa. Em I. C. Frade (Ed.), Alfabetização e seus sentidos: $O$ que sabemos, fazemos e queremos? (pp. 281-301). São Paulo: UNESP.

Frade, I. C. (2014). Alfabetização e seus sentidos: O que sabemos, fazemos e queremos? São Paulo: UNESP.

Esteban, M. T. (2012). Considerações sobre a política de avaliação da alfabetização: pensando a partir do cotidiano escolar. Revista Brasileira de Educação, 17(51), 573-592. https://doi.org/10.1590/s 1413-24782012000300005

Esteban, M. T. (2003). Sujeitos singulares e tramas complexas-desafios cotidianos e à pesquisa. Em R. L. Garcia (Org.), Método, métodos, contramétodo (pp. 125-146). São Paulo: Cortez.

Ginzburg, C. (1989). Mitos, emblemas e sinais: Morfologia e história. São Paulo: Companhia das Letras.

INEP. (2012). Prova Brasil. Brasília: Instituto Nacional de Estudos e Pesquisas Anísio Teixeira. 
INEP. (2013). Provinha Brasil. Matriz de referência para avaliação da alfabetização e do letramento inicial. Brasília: Instituto Nacional de Estudos e Pesquisas Anísio Teixeira.

INEP. (2013). Provinha Brasil. Guia correção e interpretação dos resultados. Brasília: Instituto Nacional de Estudos e Pesquisas Anísio Teixeira.

Malavasi, M. M. S. (2010). Avaliação institucional de qualidade potencializada pela participação dos vários segmentos da escola. Em E. T. Dalben (Org.), A convergências e tensões no campo da formação e do trabalho docente (pp. 84-103). Belo Horizonte: Autêntica.

Oliveira, J. B. A. e Silva, L. C. F. (2011). Para que servem os testes de alfabetização. Ensaio: Avaliação, Políticas Públicas e Educação, Rio de Janeiro, 19(73), 827-840. https://doi.org/10.1590/s0104-40362011000500006

Oliveira, R. M. (2012). Provinha Brasil: Limites e possibilidades para o trabalho pedagógico na alfabetização (Trabalho de Conclusão de Curso de Graduação). Universidade do Estado do Rio de Janeiro, Brasil.

Silva, C. S. R. e Cafieiro, D. (2010). Alfabetização e letramento de crianças de seis anos: As políticas para a implantação do ensino fundamental de nove anos. InterMeio: Revista do Programa de Pós-Graduação em Educação, Campo Grande, 16(32), 27-48.

Villas Boas, B. M. de F. e Dias, E. T. G. (2015). Provinha Brasil e avaliação formativa: Um diálogo possível? Educar em Revista, Curitiba, Brasil, Edição Especial, 1, 35-53. https://doi.org/10.1590/0104-4060.41421

\section{Breve CV do autor}

\section{Maria Océlia Mota}

Possui graduação em Pedagogia pela Faculdade de Educação da Baixada Fluminense/Universidade do Estado do Rio de Janeiro (FEBF/UERJ). Mestre em Educação, Cultura e Comunicação em Periferias Urbanas pela FEBF/UERJ. Atualmente é Doutoranda em Educação pela Pontifícia Universidade Católica - PUC-Rio. Bolsista do Conselho Nacional de Desenvolvimento Científico e Tecnológico (CNPQ). Pesquisadora do Laboratório de Avaliação da Educação - LAEd, coordenado pela Professora Alicia M. C. de Bonamino. Atuou como Professora Substituta da FEBF/UERJ. Áreas de interesse e atuação: Educação Infantil, políticas públicas da educação, avaliação da alfabetização infantil e desigualdades educacionais. ORCID ID: 0000-0002-3927-6261. Email: oceliamota@gmail.com 